ORIGINAL PROF-2236

\title{
COLORECTAL CARCINOMA
}

\section{Dr. Hamad Rana, Dr. Shahid Mahmood, Dr. Sosan Shahid, Dr. Muhammad Munir, Dr. Mulazam Hussain Bukhari}

ABSTRACT... Introduction: Prognosis is excellent in colonic carcinoma in case of well differentiated growth. All efforts must be done to diagnose the malignancy at an earlier stage for a better outcome specially if it is well differentiated growth. Objectives: To compare the different modes of presentation of carcinoma of large bowel in a tertiary care hospital and their association with pathological findings. Material \& Methods: It is a cross sectional retrospective study. Patients with histological proof of carcinoma were included in the study. Data over the period of two year was collected and analyzed. Results: This study included one hundred patients. Mean age was 49.56 years and $56 \%$ of the patients were males. $40 \%$ of the patients present between the ages of 40 to 60 years. Mean time of start of symptoms and the time of presentation in the hospital was 6.5 months ranges from 1 to 24 months. $76 \%$ of the patients had history of altered bowel habits and $60 \%$ had anorexia and weight loss. $41.66 \%$ of patients had well differentiated growth while $37.55 \%$ of patients had moderately differentiated adenocarcinoma. Conclusions: Majority of the patients with colonic carcinoma had well or moderately differentiated growth. If they are diagnosed and properly treated at an early stage, outcome is good.

Key words: Adenocarcinoma, colorectal carcinoma, well differentiated, moderately differentiated, poorly differentiated.

Article Citation

Rana H, Mahmood S, Shahid S, Munir M, Bukhari MH. Colorectal carcinoma. Professional Med J 2013;20(6): 1014-1018.

\section{INTRODUCTION}

Colorectal carcinoma is the commonest malignancy among the gastrointestinal cancers and is the second commonest in order of frequency of all malignant neoplasm 1 . Colorectal cancer ranks second after breast cancer in women and third after lung and prostate cancer in men and is one of the leading causes of cancer-related death in the United States ${ }^{2}$.

It is reported rather infrequently in this part of the world. According to Pakistan Medical Research Council's report of multicenter study on malignant tumors, malignancies of large intestine and rectum were the sixth commonest malignancies in 1973-74 whereas it moved to ninth position in 1977-803. In 1990, Iftikhar et al reported higher incidence of colorectal carcinoma in northern areas of Pakistan than neighboring countries ${ }^{4}$. In a recent study, Mahmood et al in Sheikh Zayed Hospital Lahore found colorectal carcinoma to be the commonest malignancy of gastrointestinal tract ${ }^{5}$.

Patients with carcinoma of large intestine may have three different modes of presentations. Patients may present with insidious onset of chronic symptoms, acute intestinal obstruction or peritonitis due to perforation of large gut. Depending on the location of tumor in the bowel, one or other of the following symptoms may predominate, e.g. bleeding per rectum, change in bowel habit, mucin discharge, pain, anorexia, weight loss, obstructive symptoms or palpable mass ${ }^{6}$.

Obstruction of colon by carcinoma implies a more advanced tumor and has usually been identified as a poor prognostic variable. The mortality rate can be twice as that of the non-obstructed group and the ability to perform a potentially curative resection is also low ${ }^{7}$. Perforation is the most fatal complication; the perforated tumor is associated with higher morbidity and mortality. The incidence of perforation associated with carcinoma of colon is $6-12 \%$.

Overall, colorectal cancer affects men and women approximately equally. In recent years, also there is an increase in colorectal carcinoma in younger people ${ }^{7}$. Also, there is a huge amount of literature proved strong association of dietary habits with colorectal 
carcinoma. But one interesting meta-analysis provides good evidence for an association between alcohol drinking of more than one drink per day and colorectal cancer risk ${ }^{8}$. Surgical intervention remains the mainstay of therapy for carcinoma of colon. Resections of the involved segments of colon should be performed whenever possible. The surgeon should characterize clearly whether the section has been considered curative, (in which case all of the obvious disease has been resected along with involved lymph nodes and any contagious structures), or palliative, (in which case the residual local, regional, or distant disease is present at the end of the operative procedure). The importance of this distinction cannot be overestimated because of the need for postoperative adjuvant therapies. Palliative resection is of high value in preventing obstruction, blood loss, and to improve the quality of life.

\section{MATERIAL AND METHOD}

It is a cross sectional retrospective study. Patients with histological proof of carcinoma were included in the study. Data over the period of two year was collected and analyzed.

This multicenter study was conducted in the Department of Surgery, Shalimar Medical and Dental College Lahore, Social Security Hospital Lahore and the Department of Surgery, King Edward Medical University Lahore from 1st January 2007 to 31st December 2008. Written permission was obtained from the ethical committee of hospital. Informed consent was taken from all the patients or their attendants. All patients admitted in the surgical wards of Shalimar hospital, Social Security Hospital and Mayo Hospital with colonic carcinoma were included in the study. Basic demographic details including age, gender, area of residence, marital status and duration of symptoms were taken.

\section{RESULTS}

Total 100 patients who were operated at Shalimar
Hospital, Mayo Hospital and Social Security Hospital Lahore were included in the study. Out of these, 56 (56\%) were males while 44 (44\%) were females with a male to female ratio of $1.27: 1$. Age at the time of presentation was ranging from 11 to 90 with a mean age of 49.56 .

\begin{tabular}{|l|c|}
\hline Less than 40 years & $28(28 \%)$ \\
\hline 40 to 60 years & $40(40 \%)$ \\
\hline More than 60 years & $32(32 \%)$ \\
\hline
\end{tabular}

Mean time of start of symptoms and the time of presentation in the hospital was 6.5 months ranges from 1 to 24 months. It was noted that rectal carcinoma presented earlier with a mean duration of 5 months, range 1 to 18 months as compare to colonic carcinoma where mean time of presentation was 8 months, ranges from 3 to 24 months. Among colonic group right, sided masses presented late as compare to left colonic tumors. Mean time was 9.5 month as compare to left side where mean time was 6.5 months.

Now we will discuss the pathological findings in our patients. Out of our 100 patients, none of the patient present with Duke A. Maximum number of the patients fitted into Duke $\mathrm{C}$ which had relatively poor prognosis. After that, 32\% falls into Duke B with good prognostic value.

\begin{tabular}{|c|c|}
\hline Duke A & - \\
\hline Duke B & 32 \\
\hline Duke C & 44 \\
\hline \multicolumn{2}{|c|}{ Duke D } \\
Table-Il. showing pathological findings.
\end{tabular}

In our study, majority of the patients had well or moderately differentiated growth. Only $20.79 \%$ of patients had poorly differentiated growth on 
histopathology report which had relatively poor prognosis.

\begin{tabular}{|l|l|}
\hline Well differentiated adenocarcinoma & $41.66 \%$ \\
\hline Moderately differentiated adenocarcinoma & $37.55 \%$ \\
\hline Poorly differentiated adenocarcinoma & $20.79 \%$ \\
\hline Mucin secreting adenocarcinoma & $12.55 \%$ \\
\hline Adenocarcinoma with neuro-endocrine element & $4.16 \%$ \\
\hline Malignant melanoma & $4.16 \%$ \\
\hline
\end{tabular}

Table-III. Showing degree of differentiation of growth.

We further study the type of pathology in our study. According the Department of pathology, 79.13\% specimens sent for pathology were adenocarcinoma.

\begin{tabular}{|l|c|}
\hline Adenocarcinoma & $79.13 \%$ \\
\hline Mucin secreting adenocarcinoma & $12.55 \%$ \\
\hline Adenocarcinoma with neuro endocrine element & $4.16 \%$ \\
\hline Malignant melanoma & $4.16 \%$ \\
\hline
\end{tabular}

Table-IV.

\section{DISCUSSION}

The relationship of age of patient and the diagnosis of colorectal carcinoma has been a point of discussion in many studies. In our study, male to female ratio was 1.27:1 which is comparable with Mahmood et al, WasimJafri et al, Kenda JFN et al, and Muhammad Sarfraz et $\mathrm{al}^{5,9-13}$. As compare to these studies, recently Gwen Murphy proved that male rates were higher than female rates at all sub sites for all racial and ethnic groups $^{14}$.

It was also noted that patients below the age of 40 have worst prognosis than patients above that age. Also patients above the age of 70 present at an earlier stage $^{15}$. Horn JW et al estimated that less than $5 \%$ of colorectal carcinoma occurs in patients who are less than 40 years of age but in our study $28 \%$ are younger to that age. The mean age of presentation in our study was 49.56 years. There are other studies from Pakistan ${ }^{5,16}$ which shows the same age distribution. Although several studies indicate the worst outcome for patients who develop colorectal carcinoma before the age of $40^{17,18}$. Though, there are two series suggest that younger patients have the same survival as the older ones ${ }^{19,20}$. The result of age distribution is comparable with other studies carried out in Pakistan, $^{9,11,21}$. In contrast to this, Nawa T et. al. mentioned that colorectal carcinoma is much more common in older individuals. More than $91 \%$ of patients are diagnosed with colorectal cancer over the age of $50^{22}$.

In few international studies, most colorectal adenocarcinomas $(\sim 70 \%)$ are diagnosed as moderately differentiated. Well and poorly differentiated carcinomas account for $10 \%$ and $20 \%$, respectively ${ }^{23}$. Though according to our pathology department, well differentiated growth accounts for $41.66 \%$ followed by moderately differentiated carcinoma. In the same study author mentioned that $90 \%$ of colorectal carcinomas are adenocarcinomas originating from epithelial cells of the colorectal mucosa. In our study, adenocarcinoma accounts for $80 \%$ of the total number.

Malignant Melanoma of the colon is again a very rare disease. There have been only 12 reported cases of primary melanoma of the colon to date ${ }^{24}$. We diagnosed 4 cases of malignant melanoma in our patients.

Ganglioneuromas (GNs) can be detected in different anatomical locations but are rarely found in the colon. Intestinal GNs have been found in patients with several systemic syndromes such as multiple endocrine neoplasia type IIB (MEN IIB), neurofibromatosis type 1 (NF1) (also known as von Recklinghausen's disease), juvenile polyposis, polyposis coli, tuberous sclerosis, and Cowden's disease ${ }^{25}$. Fortunately, we were also 
able to found 4 cases of adenocarcinoma with neuroendocrine element.

The overall morbidity in our study was $32 \%$ which is higher than reported by Mahmood et al 28\%5 but is comparable with Vignati PV et al, ${ }^{26}$ who reported morbidity to be $35-40 \%$. Thirty days mortality of our study was $8 \%$ higher (13.66\%) in emergency group as compared to $3.57 \%$ in the elective group.

The overall mortality rate is high as compared to overall mortality rate of $5 \%$ reported by K.K. SINGH ${ }^{27}$ but their reported $13 \%$ mortality rate of emergency patients is comparable with our study. Recently, fiftythree prospective cohort studies and 45 randomized controlled studies with 36,315 patients were published with very impressive results. The anastomotic leak rate, reported in 84 studies, was $11 \%$. The pelvic sepsis rate, in 29 studies, was $12 \%$; the postoperative death rate, in 75 studies, was $2 \%$; and the wound infection rate, in 50 studies, was $7 \%{ }^{28}$. Copyright(c) 15 Aug, 2013.

\section{REFERENCES}

1. Brian J.C. Freeman, Pradeep Madhavan, The Spine in; $R$ C G Russell, Norman S Williams, Christopher Bulstrode. Editors Bailey\& Loves Short Practice of Surgery. 25th Edition.2008 London. P 474-480.

2. MatthewFleming,SreelakshmiRavula, Sergei F. Tatishchev, and Hanlin L. Wang. Colorectal carcinoma: Pathologic aspects. J GastrointestOncol. 2012 September; 3(3): 153-173.

3. Jafery NA, Zaidi SHM: Cancer in Pakistan JPMA, 1987; 37:178-83.

4. Iftikhar et al: Colorectal Carcinoma in Northern Pakistan. A retrospective study. Pak J Surg 1990; 2 : 31-35.

5. Mahmood A et al: Colorectal cancer: Five years experience at Sheikh Zayed Hospital, Lahore. Pak. J. Surg. Oct-Dec 1995: 192-95.

6. Philip H, Gordon SathatNivatongs: Malignant neoplasm of the colon and rectum in principles and practice of surgery for the colon, rectum, anal canal. Quality Medical Publishing 2009; 23: 501-653.

7. Lisa Boardman, William E, Karnes Jr.: Epidemiology and etiology. Surgery of the colon and rectum. Churchill Livingstone 2007; 18: 335-348.

8. V. Fedirko, I. Tramacere, V. Bagnardi, M. Rota, L. Scotti et.al. Alcohol drinking and colorectal cancer risk: an overall and dose-response meta-analysis of published studies. Ann Oncol (2011) 22 (9): 19581972.doi: 10.1093/annonc/mdq653First published online: February 9, 2011.

9. WasimJafri et al: Colorectal cancer shift to right. Pak J Suerg. Dec 2006: 122-25.

10. Muhammad Sarfraz Ahmad et al: A clinicomorphological study of colorectal carcinoma at Lahore general hospital. Pak J Surg. Dec 1996: 163166.

11. Dr Ahsanul Wadood: Histochemical study of mucin, in transitional zone mucosa, colorectal carcinoma and normal mucosa. SZH, 1992.

12. Kenda JFN: Cancer of Large Bowel in Africa; 15 year study at Kinshasa, University Hospital, Zaire. Br. J Surg, 1976;63:966-68.

13. Silverberg E, Borog CL et al: Cancer Statistics. CA, 1990; 40:9-26.

14. Gwen Murphy, Susan S. Devesa, Amanda J. Cross, Peter D. Inskip, Katherine A. McGlynn, and Michael B. Cook. Sex Disparities in Colorectal Cancer Incidence by Anatomic Subsite, Race and Age. Int J Cancer. 2011 April 1;128(7): 1668-1675.

15. Bacon HE: Anus, Rectum, Sigmoid Colon: Diagnosis and Treatment, 3rf ed. Philadelphia, JB Lippincott Co. 1949:603-608.

16. Okuno M, Ikchara T, Nagayama et al: colorectal carcinoma in young adult. Am J Surg 1987;154:2647.

17. D'Onofrio GMD, Tan EGC: Is colorectal carcinoma in the young a more deadly disease? Aust NZJ Surg 1985:55:537-540. 
18. Smith C, Butler JA: Colorectal cancer in patients younger than $\mathbf{4 0}$ years of age. Dis colon rectum 1989;32: 943-846.

19. Adloff M, Arnaud JP, Schloegel M et al: Colorectal cancer in patients under $\mathbf{4 0}$ years of age. Dis colon rectum 1986; 29: 322-325.

20. Heimann TM, Oh C Aufses AH Jr.: Clinical significance of rectal cancer in young patients, Dis colon Rectum 1989; 32: 473-476.

21. Cormon ML et al: Colorectal Carcinoma. A decade of experience at the Layhey's Clinic. Dis Colon \&Rectum(1979);22:477-79.

22. Lemon S, Zapka J, Puleo E, Luckmann R, Chasen-Taber L. "Colorectal Cancer Screening Participation: Comparisons with Mammography and ProstateSpecific Antigen Screening." American Journal of Public Health (2001). 91(8): 1264-1272.

23. Matthew Fleming,SreelakshmiRavula, Sergei F. Tatishchev, and Hanlin L. Wang. Colorectal carcinoma: Pathologic aspects. J GastrointestOncol.
2012 September; 3(3): 153-173.

24. Umair Khalid, TaimurSaleem, Ayesha Mallick Imam, and Muhammad Rizwan Khan. Pathogenesis, diagnosis and management of primary melanoma of the colon. World J SurgOncol. 2011; 9: 14.

25. Enrico Fiori, Chiara Pozzessere, AntoniettaLamazza, Giovanni Leone, Francesco Borrini, Alberto Schillaci, and Pietro Mingazzini. Endoscopic treatment of ganglioneuroma of the colon associated with a lipoma: a case report. J Med Case Rep. 2012; 6: 304.

26. Vignati PV, Roberts PI. Preoperative evaluation and post operative surveillance for patients with colorectal carcinoma. SurgClin North Am 1993; 73:67-84.

27. K.K. Singh et al: Audit of colorectal cancer by non specialist surgeon. Br. J. Surg 1997; 84: 343-347.

28. Paun BC, Cassie S, MacLean AR, Dixon E, BuieWD. Postoperative complications following surgery for rectal cancer. Ann Surg. 2010 May;251(5):807-18.

\section{AUTHOR(S):}

1. DR. HAMAD RANA

Professor of Surgery,

Shalimar Medical \& Dental College Lahore

2. DR. SHAHID MAHMOOD

Professor of Surgery,

MBBS Medical College Mirpur, Govt of AJK

3. DR. SOSAN SHAHID

Consultant Radiologist,

SAARF Hospital, Islamabad

4. Dr. Muhammad Munir

Professor of Pathology.

Hashmat Medical College, Jalalpur Jattan
5. Dr. Mulazam Hussain Bukhari

Professor of Pathology, KEMU, Lahore.

Correspondence Address:

Dr. Hamad Rana

Professor of Surgery

Shalimar Medical \& Dental College Lahore

hamadrana381@gmail.com

\section{PREVIOUS RELATED STUDIES}

Ayaz Gul, Syed Iftikhar Alam, Rashid Aslam, Waqar Alam, COLORECTAL CARCINOMA; FREQUENCY OF COMMON HISTOLOGICAL TYPES IN PATIENTS BELOW 40 YEARS OFAGE PRESENTING TO TERTIARY CARE HOSPITAL (Original) Prof Med Jour 18(4) 566-570 Oct, Nov, Dec 2011.

Qaiser Mahmood, Nasreen Siddique, Ahmed ljaz Masood, COLORECTAL CARCINOMA; FREQUENCY IN SOUTHERN PUNJAB (Original) Prof Med Jour 13(2) 192-200 Apr, May, Jun, 2006. 